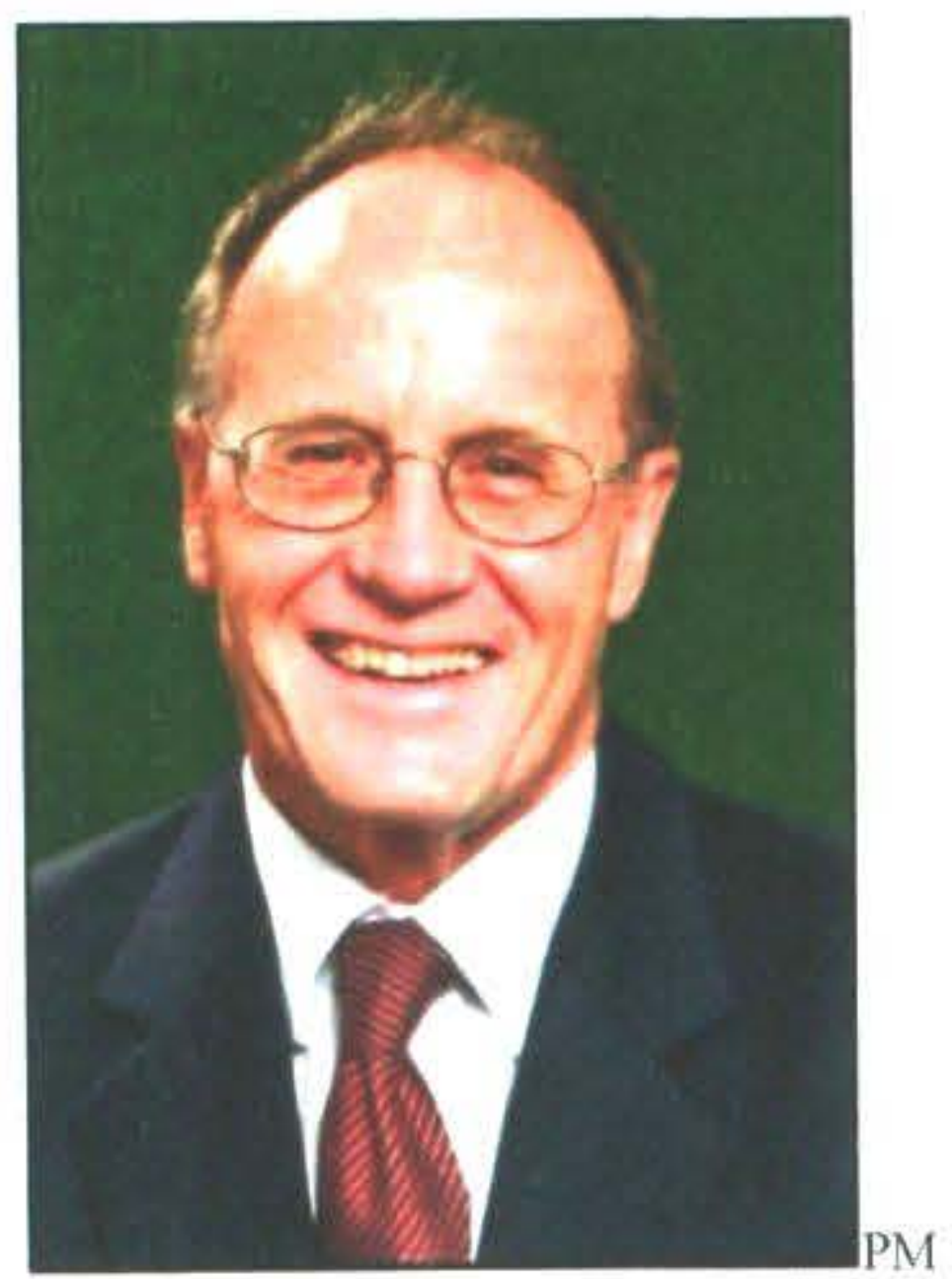

\title{
MOVING FOR EMPLOYMENT REASONS
}

\author{
Philip S. Morrison
}

School of Geography, Environment and Earth Sciences, Victoria

University of Wellington

William A.V. Clark

Department of Geography, UCLA

\section{Kirsten Nissen and Robert Didham}

\author{
Statistics New Zealand
}

\begin{abstract}
While most models of population migration assume that members of the labour force migrate to enhance returns to their labour, major surveys in the USA (PSID and CPS), in the UK (BHPS) and Australia (HILDA) all show that only around 10 percent of all individuals who change residence are motivated primarily by employment reasons. Of those moving between local labour markets only about 30 percent say they are motivated by employment reasons.

We explore this apparent paradox by drawing on evidence from the Dynamics of Motivation and Migration Survey (DMM) which recorded the reasons people of working age changed their permanent residence in New Zealand over the two year period 2005 and 2006. The need to solve the employment problem before moving means that reasons offered retrospectively for moving usually reflect a wish to adjust consumption even in the case of those moving between local labour markets. For most people of working age employment remains a necessary condition rather than sufficient reason for moving and this is why the pattern of net flows among local markets appear to support theories of migration change even though few people say they move for employment reasons.
\end{abstract}

\section{Introduction}

How we can reconcile the apparent contradiction between the strong employment based assumptions of the neoclassical model of labour migration, the pattern of net flows that seem to support the model and the weak evidence on the relative importance of employment motivators from the major social surveys? Even if we confine our attention to the employed who move between local labour markets the vast majority say they move primarily for social and consumption rather than employment reasons. The priorities people reveal in surveys support the view that contemporary changes of address, both within and between local labour markets, are undertaken primarily in order to adjust consumption rather than income.

There are two main ways of reconciling this paradox. The first is to recognise that in order to change residence members of the labour force have to sustain an income stream, predominantly through paid employment and that this in turn constrains who, when and where people can move. Those for whom employment elsewhere might be a barrier stay at home leaving only those who can solve the employment problem as movers. A minority will move expecting employment which does not eventuate precipitating either a return home or subsequent move or an adaptation at their new location (DaVanzo and Morrison, 1981). In other words movers self select according to their ability to secure employment at alternative locations as well as moving to arbitrage area differences in skill specific wages (Borjas et al., 1992).

The second reconciliation may simply reflect the fact that our empirical evidence is catching up with the growing suspicion among many migration analysts that in developed economies movement to enhance employment is increasingly giving way in relative importance to consumption or amenity based factors (e.g. Chen and Rosenthal, 2008; Clark \& Huang, 2004; Clark \& Withers, 2007; Fotheringham et al., 2000). Jobs are now sufficiently plentiful in most urban locations to allow migration to be use .o satisfy life style and associated consumption priorities.

Our results from analysing the returns from a unique survey of moving behaviour within New Zealand suggest that only a small minority of the working age population including those who change local labour markets and/or move long distances - move primarily to enhance returns 
to employment. Most change their address as a way of adjusting consumption and/or realigning social relationships and treat employment simply as an enabler rather than a motivator of movement. Nominal incomes therefore change little after most moves. Consumption, primarily of housing, still remains firmly embedded within labour market catchments and therefore net migration flows continue to coincide with the geography of employment growth. To jump from this empirical correlation and infer that people move primarily to improve their employment prospects, both opportunities and wages, is inconsistent with our survey evidence. For most movers employment considerations remain passive rather than active; on-going employment is viewed as a necessary condition for the move rather than sufficient reason for moving.

The policy implications of this evidence are consistent with the growing attention being paid to the role of amenity in attracting labour. The local challenge lies in setting an economic base that will enable potential migrants to secure the employment they need in order to realise the goals which are their primary motivators for moving: material consumption, environment, life style and family.

\section{Outline}

We present the paper in nine sections. Section 1 backgrounds the argument by contrasting the investment (labour) and consumption (amenity) approaches to internal migration. Section 2 introduces the data on reported motivations for mobility as collected by the Dynamics of Motivation of Mobility (DMM) survey initiated and run by Statistics New Zealand. In section $\mathbf{3}$ we distinguish between mobility and migration by partitioning the country into local labour markets.

Section 4 reports the non-motivational evidence - the extent to which mobility varies by labour force status and by occupation - controlling for age, sex and ethnicity. In section 5 we turn to the motivational evidence and highlight the variety of employment reasons people offer for moving. Section 6 presents the employment reasons for moving and in section 7 we compare distances moved within and between LMAs. In section 8 we attempt to identify the characteristics of those who move for employment reasons. Our conclusions are presented in section 9.

\section{Section 1. Background}

The standard human capital model of migration views an individual's decision to move as conditional upon the net discounted returns they expect to receive from movement exceeding those they expect ${ }^{\text {he }}$ from staying, notwithstanding the general uncertainty typically surrounding the moving decision (Kan, 1999; Khwaja, 2002). In the labour mobility version of the model the returns to employment are the product of the probability of being offered a job of interest times the expected wage. If the employment returns (net of moving costs) at an alternative destination exceed those prevailing at the origin then the migration is assumed to take place.

Such an argument is of long standing. It was implicit in Ravenstein's nineteenth century papers and was elaborated by Hicks in the 1930s (Grigg, 1977). "Differences in net economic advantages, chiefly differences in wages, are the main causes of migration," Hicks argued in his 1932 treatise (p. 76) (Boheim and Taylor, 2007) p 99. ${ }^{2}$ The same argument is central to the arguments of Sjaastad (1962) and is applied to migration within developing countries by Harris and Todaro (1970). The standard economic model of migration therefore treats the decision to change geographic location as a human capital investment designed to enhance the decision-maker's prospects in the labour market (Blackburn, 2006) p. 1.

Although not logically precluded by the investment model, what the burgeoning literature on the role of local amenities suggests is that for the majority of the population within developed economies, a change of residential location can also be treated as a consumption decision, that is one designed to enhance quality of life and satisfaction with the region, neighbourhood and residence. The distribution of preferences across investment and consumption returns can be expected to vary between households and presumably even within them. It has been suggested for example that households in general prefer non-metropolitan areas and cities in warm coastal locations while firms tend to prefer large, growing cities attractive to workers with high levels of education (Chen and Rosenthal, 2008). Different mixes of investment and consumption criteria by households are therefore likely to lead to different location decisions.

The expected returns to migration can depend upon whose migration we are addressing; whether for example the migrant is a supplier of labour, an investor, a consumer and/or a producer (Shields and Shields, 1989). For some, the migration is driven by improving employment conditions or promotion prospects but for others enhancing consumption opportunities including the social are paramount. Indeed, instead of being alternatives, investment and consumption returns may be complementary, the mix varying case by case. ${ }^{3}$ The literature on compensating differentials is largely designed to address this fact - that people will forego pure wage returns for life style and quality of life returns (Rosen, 1986). That a mix of investment and consumption motivations can co-exist reflects the fact that in affluent economies levels of employment are sufficiently high throughout the country for workers to adjust their consumption by changing where they live.

Such results are not inconsistent with the evidence on net migration flows. According to the neoclassical migration model employment growth differentials between origin and destination should account for at least some of the variation in net migration. So in the New Zealand case we explore below, Maré and Timmins find that people move to areas of high employment growth; that when the demand for labour in a region or local labour market rises some of this demand will be met by the supply of workers 
from other regions. A positive correlation between employment and growth in an LMA are therefore consistent with higher rates of migrant inflows and lower rates of outflows (Maré and Timmins, 2004). Our point in this paper is that it is not necessary to assume that people treat mobility as an investment in employment to generate such results. It is sufficient to recognise that the need for on-going employment even without any income change will constrain net flows to certain locations. The minority moving to enhance employment opportunities will simply exaggerate this same geographical pattern of net gains and losses.

\section{Section 2. Data}

The Dynamics of Motivation and Migration Survey (DMM) is a Statistics New Zealand initiative designed to investigate the motivations behind mobility (and implicitly residential stability). Although New Zealand has very good data on mobility patterns from their five yearly census the country knows very little about why some people move from one place of residence to another and others stay put, or why they choose certain locations and not others. Therefore a survey was designed to collect open ended reasons for why people are attracted to, disaffected by, or attached to where they live (Nissen and Didham, 2008). ${ }^{4}$ Under our contract with Statistics
New Zealand we have access to the full set of individual responses to the resulting DMM survey through their secure data laboratory which was set up and monitored to guard respondent confidentiality.

The DMM survey was run as a supplement to the March 2007 quarter of the New Zealand Household Labour Force Survey (HFLS) between 7 January to 7 April 2007. The quarterly HFLS routinely collects basic demographic and employment information from around 15,000 private households $(30,000$ individuals $)$ on a statistically representative basis from rural and urban areas throughout the country. In the March 2007 quarter the HLFS received a sample of 26,756 individual responses and all were given the opportunity to take part in the DMM supplement with 23, 465 completing the additional questions.

The DMM survey separates the sampled population into three mobility categories depending on whether they moved in the two years prior to the interview, that is between 2005 and 2007. They are then asked whether they last moved within New Zealand or to New Zealand (from Australia) as depicted in Figure 1. Questions on plans to move are asked over the subsequent two years to 2009 of all three mover categories.

\section{Figure 1: The structure of the Dynamics of Motivation and Migration (DMM) survey}

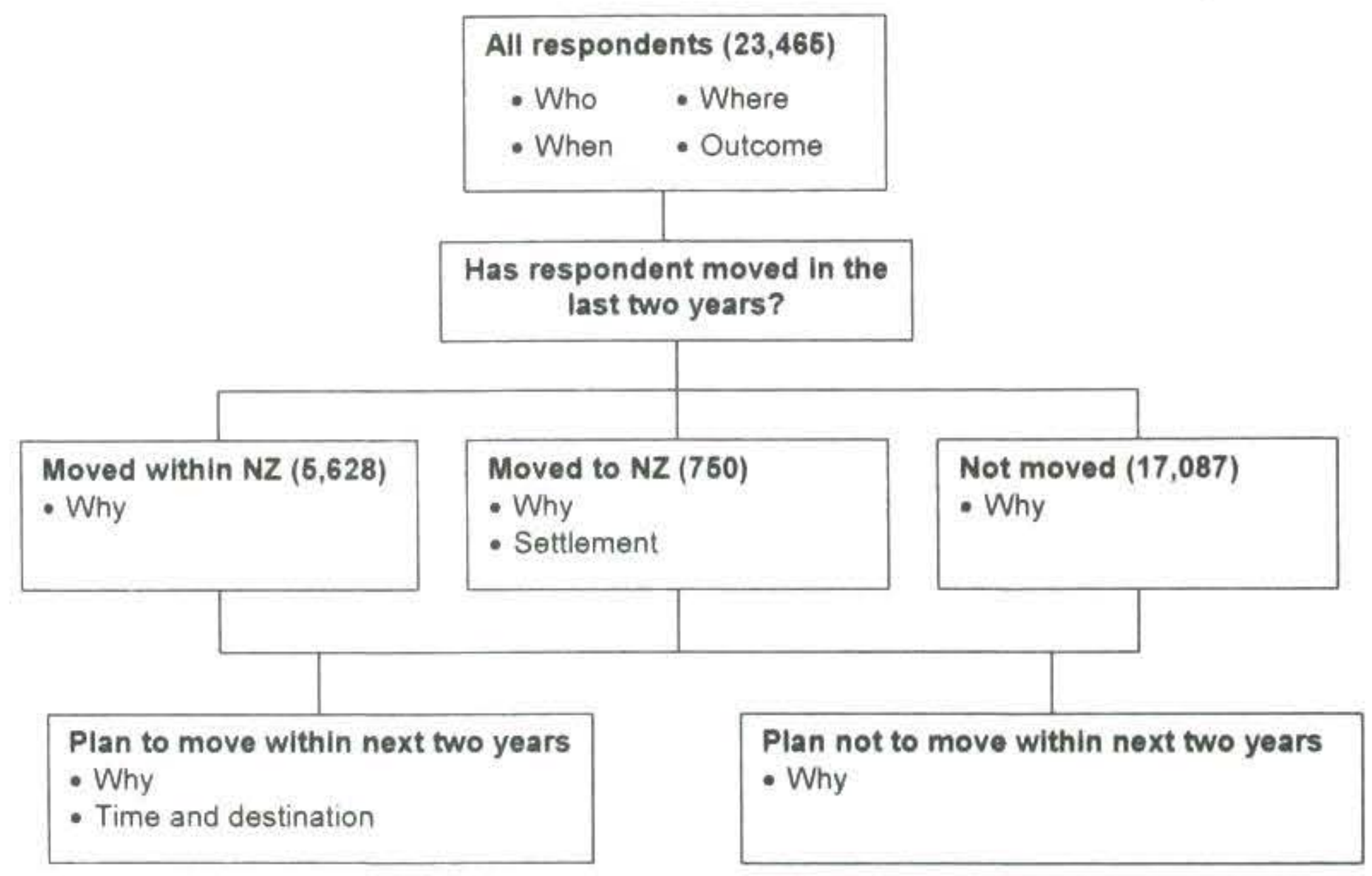

Source: (Nissen and Didham, 2008)

While changes of address are recorded by the DMM survey the state of employment is identified simply as a labour market state at the beginning of the period, i.e. the respondent is employed, unemployed or not in the labour force. If the person is employed they also give their occupation. This information is recorded at the beginning of the two year period 2005 and 2006 for all those employed and for movers again just before their last change of address.

Movers are asked why they moved and stayers why they stayed. The two sets of responses are coded in almost exactly the same way. While it is possible to identify just how employment factors feature in the responses of both groups, our analysis here is confined to movers (of working age). ${ }^{6}$

In summary, after almost a decade of lobbying, Statistics New Zealand invested in what is a unique survey of (mainly internal) migrants with the explicit intention of identifying the reasons people offer for remaining in or changing their address. The data complement the five yearly census figures which show in considerable demographic detail the number moving, the rate of mobility and the direction of movement but give little indication as to why people move. 


\section{Section 3. Mobility or migration?}

It is commonly assumed that, "a move is a migration when the worker leaves one housing-and-labour market to relocate in another" (Zax, 1993) p 358. Notwithstanding the question this begs about how the boundaries of such markets are determined (Morrison, 2005), the purpose of migration Zax argues is, "to exploit differences between the housing price and wage combinations available in different regions, generated by differences in local amenities, access to markets, production technologies or a variety of other causes." (Ibid). Migration therefore arbitrages differences between the joint housing and employment opportunities available in different markets" (Zax, 1993) p 350,1. By contrast (intra-urban) mobility, "exploits differences between locations on the same housing price and wage functions, generated by the costs of the journey-to-work" (Ibid, my emphasis). In the mobility case job and housing relocation are substitutes (only one changes usually); in the case of migration they are complements, for they both change (Zax, 1991).

The onus is on the researcher to establish whether a change of residence involves moving along or between housing price and wage functions. In practice this is usually done by determining some boundary between the commuting sheds used to define local labour (and hence housing) markets. Applying the adage that migration begins where commuting ends, we draw on a geographical partitioning of the New Zealand labour market (Papps and Newell, 2002). The algorithm we used identifies sites of employment and the proportions of workers who commuted in and out in 2006 and applies a decision rule that delimits the geographic boundaries between adjacent labour markets. We have chosen a relatively fine spatial division of the country into a set of 104 LMAs in order to explore the role of employment motivation plays in moves between and within local labour market areas. With this partitioning in place we turn firstly to the non-motivational evidence for the role of labour force status and human capital on mobility and migration and then to the motivational reasons for moving.

\section{Section 4. The propensity to move: the non- motivational evidence}

Tests of the neoclassical assumptions underpinning internal migration usually focus on the behaviour of the unemployed because of their documented sensitivity to the differing vacancy rates across the country (Ritchey, 1976; Saben, 1964). For example Herzog, in his review of eleven micro-data multivariate studies of the propensity to move noted how, "personal unemployment significantly augments migration likelihood in nine of the ten studies that represent such joblessness by a binary variable" (Herzog et al., 1993), p 330. More recently Broheim and Taylor used the first seven waves of the British Household Panel Survey (BHPS) covering 1991 to 1999 to demonstrate that the unemployed do indeed have a higher probability of moving (Boheim and Taylor, 2000). ? $^{7}$
Such evidence is not always accepted uncritically however. McCormick for one argues that a correlation between individual unemployment and out-migration does not always justify the conclusion that such moves are "spurred by this to change location in search of better economic opportunity" because they "do not identify the reasons for the move" (McCormick, 1997) p 587 as cited in Gregg (Gregg et al., 2004), p 380. Gordon had similar concerns, arguing that the unemployed move largely for structural reasons beyond their control; they are pushed away from their local labour market in effect and in this sense they are involuntary movers (or unsponsored workers in Gordon's terminology).

In order to identify the role labour force status and employment characteristics play in accounting for change of address in New Zealand we applied the following model. Since individuals can make adjustments along as well as between housing price and wage functions and refer to both as employment adjustments we apply the same model to moves within and between local labour markets, namely:

$$
\mathrm{p}(\mathrm{m})_{\mathrm{i}}=\mathrm{E}_{\mathrm{i}} \beta,+\mathrm{X}_{\mathrm{i}} \beta+\varepsilon_{\mathrm{i}}
$$

where the probability of moving over a given period, $\mathrm{p}(\mathrm{m})$, is a function of the employment status characteristics of the respondent $\mathrm{E}$, controlling for a matrix of demographic and human capital attributes $\mathrm{X}$. The available variables are listed in Table 1 together with their mean and standard deviations across the sample for males and females separately. The Vectors $\beta$ refer to the parameters to be estimated.

Over one quarter of the New Zealand population moved within the two year period 2005 and 2006, and if we confine our attention to the working age population $(15<65$ years $)$ then the proportion rises to 29 percent. Among those working for pay or profit the proportion rises even higher and if we confine our analysis just to the unemployed, the proportion moving reaches 43 percent. $^{8}$ On the face of it therefore the propensity to move in New Zealand does appear to be influenced by peoples prior labour force status.

Any such generalisation are likely to be subject to composition bias. In the case of unemployment for example, the fact that over two fifths change their permanent residence over the two year period could simply reflect their youth and the integral 'chaos' which is characteristic of young people's labour market (Blanchflower, 1996; Topel and Ward, 1992). To obtain estimates of the marginal influence of employment status on the probability of moving we need to control for a range of other possible characteristics that might influence peoples propensity to move. These include age in decades against those aged $35<45$ as the base, education (with the presence of school and post-school qualifications as the base), ethnicity (Maori and Pacific Island Polynesian, compared against the base of European plus other) and whether the respondent was born in New Zealand. 
Table 1: Descriptive statistics of the working age men and women $(16<65)$. New Zealand 2007

\begin{tabular}{|c|c|c|}
\hline \multicolumn{3}{|l|}{ Male } \\
\hline Variation & Mean & $\begin{array}{l}\text { Standard } \\
\text { deviation }\end{array}$ \\
\hline \multicolumn{3}{|l|}{ Labour force status } \\
\hline The labour force & 0.838 & 0.368 \\
\hline The employed & 0.799 & 0.401 \\
\hline The unemployed & 0.039 & 0.194 \\
\hline \multicolumn{3}{|l|}{ Demographics } \\
\hline Age 16-24 & 0.186 & 0.389 \\
\hline Age $25-34$ & 0.177 & 0.382 \\
\hline Age $35-44$ & 0.230 & 0.420 \\
\hline Age $45-54$ & 0.229 & 0.420 \\
\hline Age $55-64$ & 0.179 & 0.383 \\
\hline Proportion with no qualifications & 0.381 & 0.486 \\
\hline Qualifications since leaving school & 0.579 & 0.490 \\
\hline Maori & 0.118 & 0.323 \\
\hline Pacific Island Polynesian & 0.066 & 0.247 \\
\hline Chinese & 0.028 & 0.164 \\
\hline Indian & 0.033 & 0.179 \\
\hline Born in New Zealand & 0.766 & 0.424 \\
\hline \multicolumn{3}{|l|}{ Occupation } \\
\hline Legislators & 0.130 & 0.336 \\
\hline Professionals & 0.142 & 0.349 \\
\hline Technicians & 0.103 & 0.304 \\
\hline Clerks & 0.047 & 0.213 \\
\hline Service and sales & 0.078 & 0.268 \\
\hline Agriculture & 0.096 & 0.295 \\
\hline Trades workers & 0.188 & 0.391 \\
\hline Plant and machinery & 0.142 & 0.349 \\
\hline Labourers & 0.065 & 0.246 \\
\hline Response unidentifiable & 0.008 & 0.089 \\
\hline \multicolumn{3}{|l|}{ Female } \\
\hline \multicolumn{3}{|l|}{ Labour force status } \\
\hline The labour force & 0.709 & 0.454 \\
\hline The employed & 0.095 & 0.294 \\
\hline The unemployed & 0.128 & 0.334 \\
\hline \multicolumn{3}{|l|}{ Demographics } \\
\hline Age 16-24 & 0.163 & 0.370 \\
\hline Age $25-34$ & 0.194 & 0.395 \\
\hline Age $35-44$ & 0.246 & 0.431 \\
\hline Age $45-54$ & 0.223 & 0.416 \\
\hline Age $55-64$ & 0.174 & 0.379 \\
\hline Proportion with no qualifications & 0.405 & 0.491 \\
\hline Qualifications since leaving school & 0.568 & 0.495 \\
\hline Maori & 0.143 & 0.350 \\
\hline Pacific Island Polynesian & 0.065 & 0.245 \\
\hline Chinese & 0.029 & 0.168 \\
\hline Indian & 0.026 & 0.160 \\
\hline Born in New Zealand & 0.774 & 0.418 \\
\hline \multicolumn{3}{|l|}{ Occupation } \\
\hline Legislators & 0.119 & 0.323 \\
\hline Professionals & 0.194 & 0.395 \\
\hline Technicians & 0.145 & 0.352 \\
\hline Clerks & 0.188 & 0.391 \\
\hline Service and sales & 0.202 & 0.401 \\
\hline Agriculture & 0.044 & 0.206 \\
\hline Trades workers & 0.011 & 0.102 \\
\hline Plant and machinery & 0.039 & 0.193 \\
\hline Labourers & 0.052 & 0.223 \\
\hline Response unidentifiable & 0.007 & 0.084 \\
\hline
\end{tabular}

We apply model 1 by regressing the log odds of changing of address within the two year survey period on being employed and being unemployed for men and women separately (against being 'not in the labour force')." Post-estimating the marginal effects of the independent variables from the logit model allows us to interpret the estimates as probabilities as in Table 2. The coefficients in column one of Table 2 report the discrete change of each successive independent variable from 0 to 1 on the probability that these respondent moved, while holding the values of the remaining independent variables at their means (column five).

We learn from Table 2 that unemployed males are 16.1 percent more likely to have moved than men who were not in the labour force (including those who otherwise refused to answer or didn't know) but that employed males were only 4.2 percent more likely to move, a result that is only statistically significant at $p>0.1$. Therefore as far as males are concerned, their employment status is only a very weak guide to the likelihood of their changing permanent residence.

In the female case, the impact of two employment status groups is reversed; it is the employed who are relatively more likely to move ( 7.0 percent over the base) and, although yielding a marginal probability of about five percent, unemployed females were not significantly more likely to move than those not in the labour force. ${ }^{10}$ In short, prior labour force status does not appear to be a strong influence on residential mobility among women either.

The other major assumption about labour migration is its positive relationship to human capital. Professionals are typically considered more mobile than manual workers for example. Mobility rates have been shown to decline with human capital and rise only when people become unemployed. The resulting $U$ shape of the probability of moving over the occupational domain, as argued by (Lee, 1966), was empirically verified several years later on USA data for an age standardised population (Zodgekar and Seetharam, 1972). Similar arguments summarising Lansing and Mueller's early work on this point (Lansing and Mueller, 1967) appeared in Ritchey (1976) and have been presented by Gordon (1995). Unlike the unemployed who move largely for reasons beyond their control, white collar/skilled workers are motivated to move by the expected rate of return as viewed by themselves or their "sponsors' within the firm. ${ }^{11}$ On the basis of the labour mobility model one would expect those occupations containing the more highly educated to have a greater incentive to move largely to exploit the specialised city infrastructures, particularly if they do not already reside in such environments. ${ }^{12}$ 
Table 2: The influence of prior employment status on the probability of changing permanent residence within New Zealand over the two year period 2005 and 2006. Men and women aged 18 to 65 years.

Males

\begin{tabular}{lrrrrr}
\hline Variable & dy/dx & Std.Err. & $z$ & $P>|z|$ & Mean \\
\hline Age 16-24 & 0.139 & 0.021 & 6.47 & 0.000 & 0.131 \\
Age 25-34 & 0.124 & 0.017 & 7.11 & 0.000 & 0.181 \\
Age 45-54 & -0.115 & 0.013 & -8.84 & 0.000 & 0.253 \\
Age 55-64 & -0.187 & 0.012 & -15.19 & 0.000 & 0.179 \\
Proportion with no qualifications & 0.002 & 0.012 & 0.18 & 0.858 & 1.344 \\
One or more qualifications since leaving school & 0.055 & 0.011 & 4.71 & 0.000 & 0.592 \\
Employed & 0.041 & 0.021 & 1.91 & 0.056 & 0.922 \\
Unemployed & 0.161 & 0.050 & 3.19 & 0.001 & 0.021 \\
Maori & 0.023 & 0.018 & 1.25 & 0.211 & 0.102 \\
Pacific Island Polynesian & -0.014 & 0.023 & -0.60 & 0.549 & 0.051 \\
Chinese & 0.013 & 0.035 & 0.37 & 0.714 & 0.023 \\
Indian & 0.076 & 0.035 & 2.15 & 0.032 & 0.031 \\
Born in New Zealand & -0.050 & 0.016 & -3.12 & 0.002 & 0.792 \\
\hline
\end{tabular}

$\mathrm{N}=6645 . \mathrm{LR}$ chi2 (13) $590.29, \mathrm{Prob}>$ chi2 $=0.0000$, pseudo $\mathrm{R} 2=0.075$. Overall probability of changing residence over the period is 0.253 .

Females

\begin{tabular}{lrrrrr}
\hline Variable & dy/dx & Std.Err. & $\mathrm{z}$ & $\mathrm{P}>|\mathrm{z}|$ & $\mathrm{Mean}$ \\
\hline Age 16-24 & 0.210 & 0.021 & 9.79 & 0.000 & 0.128 \\
Age 25-34 & 0.177 & 0.017 & 10.02 & 0.000 & 0.183 \\
Age 45-54 & -0.097 & 0.013 & -7.42 & 0.000 & 0.261 \\
Age 55-64 & -0.175 & 0.012 & -13.90 & 0.000 & 0.160 \\
Proportion with no qualifications & 0.009 & 0.012 & 0.78 & 0.436 & 1.306 \\
One or more qualifications since leaving school & 0.038 & 0.011 & 3.39 & 0.001 & 0.562 \\
Employed & 0.069 & 0.015 & 4.62 & 0.000 & 0.868 \\
Unemployed & 0.049 & 0.038 & 1.29 & 0.196 & 0.026 \\
Maori & 0.034 & 0.016 & 2.02 & 0.044 & 0.124 \\
Pacific Island Polynesian & -0.096 & 0.019 & -4.98 & 0.000 & 0.049 \\
Chinese & -0.071 & 0.028 & -2.56 & 0.011 & 0.023 \\
Indian & -0.056 & 0.029 & -1.92 & 0.055 & 0.023 \\
Born in New Zealand & -0.055 & 0.015 & -3.48 & 0.000 & 0.801 \\
\hline
\end{tabular}

$\mathrm{N}=7021, \mathrm{LR}$ chi(13), prob $>$ chi2 $=0.000$, pseudo $\mathrm{R} 2=0.075$. Overall probability of changing residence over the period is 0.251 .

Source: Statistics New Zealand, Dynamics of Motivation and Migration Survey (DMM).

Table 3 presents the results of replacing employment status by occupation using the largest group, Sales and Service workers as the base. These New Zealand results offer only weak evidence of any difference in the propensity of manual and non-manual workers to move. In the male case, agriculture, trades workers and labourers all show a lower probability of moving although in no case does the probability fall more than six percent between the Sales and Service base and any other occupational group. In the female case those referred to as Legislators (includes Managers and Administrators) do show a greater probability of moving - relative to Sales and Service workers.

In summary, considering the probability of any change of address, neither labour force status nor occupation appear to play a major role in identifying who is likely to move, among men or women. This could of course be due to the confounding of intra and inter-local labour market moves for two thirds of all movement takes place within LMAs. We turn therefore to the quarter of the population who are movers and explore the degree to which their propensity to move between local labour markets is influenced by their labour force and occupational status prior to the move.
We employ the same model as in equation 1 replacing the probability of moving per se by the probability of moving between as opposed to within local labour markets (results available on request). From this evidence we observe that being employed actually raises the probability of moving within rather than between local labour markets (controlling for age, education and ethnic differences). The result is statistically significant for males but not for females. Women show a much higher probability of changing labour markets if they are unemployed than do men, possibly because they are more likely to have more 'geographically portable' skills across the less geographically differentiated service sector.

Occupation also has little marginal effect on whether movers leave their local labour market, again with the exception of female professionals who are more likely to move to another local labour market. (Male and female agricultural workers are twice and three times as likely to leave town respectively but largely for seasonal reasons).

In summary, while employment enables residential mobility and unemployment promotes it, labour force status prior to the move has little conditional effect on whether someone in the working age groups changes their address and whether it takes place within or between 
local labour markets - except in the case of female professionals (and all agricultural workers). With this non-motivational evidence in place we now turn to the circumstances under which moves explicitly motivated by employment take place.

Table 3: The influence of prior occupation on the probability of changing permanent residence within New Zealand over the two year period 2005 and 2006, for men and women $18<65$ years.

\section{Males}

\begin{tabular}{lrrrrr}
\hline Variable & dy/dx & Std.Err. & $z$ & $P>|z|$ & $X$ \\
\hline Age 16-24 & 0.216 & 0.024 & 8.70 & 0.000 & 0.096 \\
Age 25-34 & 0.126 & 0.017 & 7.08 & 0.000 & 0.187 \\
Age 45-54 & -0.122 & 0.013 & -9.35 & 0.000 & 0.265 \\
Age 55-64 & -0.188 & 0.012 & -15.26 & 0.000 & 0.188 \\
Proportion with no qualifications & 0.005 & 0.013 & 0.38 & 0.708 & 1.342 \\
One or more qualifications since leaving school & 0.043 & 0.012 & 3.49 & 0.000 & 0.610 \\
Legislators & 0.003 & 0.024 & 0.15 & 0.882 & 0.130 \\
Professionals & -0.033 & 0.022 & -1.48 & 0.139 & 0.138 \\
Technicians & 0.004 & 0.025 & 0.16 & 0.876 & 0.103 \\
Clerks & -0.047 & 0.028 & -1.67 & 0.095 & 0.046 \\
Agriculture workers & -0.062 & 0.022 & -2.72 & 0.007 & 0.098 \\
Trades workers & -0.052 & 0.020 & -2.55 & 0.011 & 0.187 \\
Plant and machinery operators & -0.027 & 0.023 & -1.18 & 0.238 & 0.144 \\
Labourers & -0.049 & 0.025 & -1.93 & 0.054 & 0.065 \\
Response unidentifiable & -0.129 & 0.040 & -3.22 & 0.001 & 0.008 \\
Maori & 0.024 & 0.019 & 1.21 & 0.228 & 0.098 \\
Pacific Island Polynesian & -0.034 & 0.023 & -1.46 & 0.146 & 0.049 \\
Chinese & -0.017 & 0.035 & -0.50 & 0.620 & 0.021 \\
Indian & 0.056 & 0.036 & 1.56 & 0.118 & 0.030 \\
Born in New Zealand & -0.054 & 0.017 & -3.22 & 0.001 & 0.792 \\
\hline
\end{tabular}

Note: $\mathrm{N}=6122, \mathrm{LR}$ chi2 $(20)=641.44$, prob $>$ chi2 $=0.000$, pseudo $\mathrm{R} 2=0.090$

\section{Females}

\begin{tabular}{lrrrrr}
\hline Variable & $\mathrm{dy} / \mathrm{dx}$ & Std.Err. & $\mathrm{z}$ & $\mathrm{P}>|\mathrm{z}|$ & $\mathrm{X}$ \\
\hline Age 16-24 & 0.262 & 0.025 & 10.21 & 0.000 & 0.094 \\
Age 25-34 & 0.184 & 0.018 & 9.75 & 0.000 & 0.183 \\
Age 45-54 & -0.097 & 0.013 & -7.10 & 0.000 & 0.281 \\
Age 55-64 & -0.183 & 0.013 & -14.03 & 0.000 & 0.171 \\
Proportion with no qualifications & 0.009 & 0.014 & 0.68 & 0.495 & 1.302 \\
One or more qualifications since leaving school & 0.039 & 0.012 & 3.11 & 0.002 & 0.577 \\
Legislators & 0.048 & 0.022 & 2.13 & 0.033 & 0.118 \\
Professionals & -0.013 & 0.019 & -0.69 & 0.493 & 0.190 \\
Technicians & -0.001 & 0.019 & -0.09 & 0.925 & 0.146 \\
Clerks & -0.011 & 0.018 & -0.64 & 0.522 & 0.188 \\
Agriculture workers & -0.031 & 0.028 & -1.09 & 0.276 & 0.045 \\
Trades workers & -0.051 & 0.049 & -1.03 & 0.301 & 0.010 \\
Plant and machinery operators & -0.027 & 0.030 & -0.92 & 0.356 & 0.039 \\
Labourers & 0.032 & 0.029 & 1.09 & 0.277 & 0.053 \\
Response unidentifiable & -0.057 & 0.059 & -0.97 & 0.334 & 0.006 \\
Maori & 0.024 & 0.018 & 1.33 & 0.185 & 0.118 \\
Pacific Island Polynesian & -0.074 & 0.022 & -3.30 & 0.001 & 0.046 \\
Chinese & -0.056 & 0.032 & -1.73 & 0.083 & 0.021 \\
Indian & -0.049 & 0.031 & -1.55 & 0.122 & 0.023 \\
Born in New Zealand & -0.041 & 0.016 & -2.47 & 0.014 & 0.803 \\
\hline
\end{tabular}

Note: $\mathrm{N}=6090, \mathrm{LR}$ chi2 $(20)=686.32$, prob $>$ chi2 $=0.000$, pseudo $\mathrm{R} 2=0.096$

Source: Statistics New Zealand, Dynamics of Motivation and Migration Survey (DMM).

\section{Section 5. Reasons for moving: the motivational evidence}

The quarter of the population who changed residence within New Zealand over the two years 2005 and 2006, were asked why they did or did not move and to venture all the reasons they could think of. Among movers typical responses included: 'no employment (locally)', 'didn't have a choice', 'separated from my husband', 'to get a job nearby', 'had money to buy this house', 'didn't get along with my parents', etc.

Answers like these were then post coded to around 70 reasons (level 3 ) which were in turn collapsed into 35 broader categories (level 2) and then finally in to seven categories (level 1). ${ }^{13}$ With two exceptions we have accepted the default coding from level three to two. ${ }^{14}$ Most respondents only ventured one reason for moving 
and those, together with the primary reason by those offering multiple responses, are analysed here. ${ }^{15}$

The distribution of responses over the main reason for moving from the place of origin are given in Table 4 and are quite consistent with the distributions found in most 'reasons for moving' surveys. ${ }^{16}$ Housing cost and housing size/satisfaction together account for over half of all reasons for moving: $32.37+21.18=53.55$ and this rises by 9.18 percent to nearly 63 percent if environmental reasons are included. A further 19 percent of moves were motivated by social reasons and an additional 4.2 percent for educational reasons. This leaves only about one in ten movers citing employment reasons as their main reason for moving (10.65 percent in this instance).

Table 4: Main reasons for moving from previous residence to new residence

\begin{tabular}{lrrr}
\hline & Frequency & Percent & Cumulative Percent \\
\hline Social & 1,016 & 18.88 & 18.88 \\
Education & 226 & 4.20 & 23.08 \\
Employment & 573 & 10.65 & 33.72 \\
Housing cost & 1742 & 32.37 & 66.09 \\
Housing size/satisfaction & 1140 & 21.18 & 87.27 \\
Environment & 494 & 9.18 & 96.45 \\
Other reasons & 171 & 3.18 & 99.63 \\
No response & 20 & 0.37 & 100.00 \\
\hline Total & 5,382 & 100.00 & \\
\hline
\end{tabular}

Source: Statistics New Zealand, Dynamics of Motivation and Migration Survey (DMM).

To what extent do these reasons for moving vary depending on whether the moves take place within or between local labour markets? The evidence is most simply displayed in Table 5 . We find that just under twothirds of all men who cite employment reasons and over two-thirds of all women in the workforce are moving between rather than within their LMA, a result which previous evidence leads us to expect. However only around twelve percent of men and nine percent of women actually say they move for employment reasons and finding that less than one in three movers between local labour markets is not motivated primarily by employment reasons is something of a surprise given the emphasis placed on employment differentials in the theory of migration.

Table 5: Employment and non-employment motivations for moving within or between local labour markets in New Zealand. Male and female $18<65$ years.

(Row and column percentages in italics)

\section{Males}

\begin{tabular}{lccc}
\hline & \multicolumn{2}{c}{ InterLMA Dep } & \\
& Intra-LMA & Inter-LMA & Total \\
\hline Non-employment reasons & 1,365 & 305 & 1,670 \\
& 81.7 & 18.3 & 100.0 \\
Employment Reasons & 94.5 & 66.7 & 87.8 \\
& 80 & 152 & 232 \\
& 34.5 & 65.5 & 100.0 \\
Total & 5.5 & 33.3 & 12.2 \\
& 1,445 & 457 & 1,902 \\
& 76.0 & 24.0 & 100.0 \\
& 100.0 & 100.0 & 100.0 \\
\hline
\end{tabular}

\section{Females}

\begin{tabular}{lccc}
\hline & \multicolumn{2}{c}{ InterLMA Dep } & \\
& Intra-LMA & Inter-LMA & Total \\
\hline Non-employment reasons & 1,856 & 422 & 2,278 \\
& 81.5 & 18.5 & 100.0 \\
Employment Reasons & 96.2 & 72.0 & 90.5 \\
& 74.0 & 164.0 & 238.0 \\
& 31.1 & 68.9 & 100.0 \\
\hline Total & 3.8 & 28.0 & 9.5 \\
& 1,930 & 586 & 2,516 \\
& 76.7 & 23.3 & 100.0 \\
& 100.0 & 100.0 & 100.0 \\
\hline
\end{tabular}

Source: Statistics New Zealand, Dynamics of Motivation and Migration Survey (DMM). 
The other unexpected finding concerned the role employment motivations played in moves within LMAs, given previous disavowal of its role in intra-urban mobility (Simmons, 1968) p. 637. Employment motivations are clearly not confined to those who change their LMA, in fact over and just under one third of male and female movers respectively [within LMAs] said they moved for employment reasons. There are now two further issues which require our attention. The first concerns the meaning of 'employment reason' and how respondents' answers are assembled by coders into that category. The second is the way the different employment reasons are themselves distributed within and between LMAs.

\section{Section 6. Employment reasons for moving}

The major social surveys cited in the abstract simply report 'employment' reasons for moving. Our ability to look in more detail at the employment reasons offered by respondents allows us to see what might be driving not only the relationship between employment and mobility but how people reflect on that relationship. Consider the breakdown of employment reasons into the following six categories for example: those in which respondents are moving voluntarily for a new job or for promotion and three other categories which reflect involuntary or external demand driven factors: transfers, losing a job and retirement. A sixth category, moves motivated by wanting to live closer to work, is also tabulated in Table 6 along with a residual of other reasons.

Table 6: Main employment reasons for moving from previous residence

\begin{tabular}{lrrr}
\hline $\begin{array}{l}\text { Employment reasons for moving } \\
\text { from origin }\end{array}$ & Frequency & Percent & $\begin{array}{r}\text { Cumulative } \\
\text { Percent }\end{array}$ \\
\hline To take up new job promotion & 135 & 23.56 & 23.56 \\
Look for job & 127 & 22.16 & 45.72 \\
Transfer & 35 & 6.11 & 51.83 \\
Lost job & 31 & 5.41 & 57.24 \\
Retired & 31 & 5.41 & 62.65 \\
To be closer to workplace & 93 & 16.23 & 78.88 \\
Other reasons & 121 & 21.12 & 100.00 \\
\hline Total & 573 & 100.00 & \\
\hline
\end{tabular}

Source: Statistics New Zealand, Dynamics of Motivation and Migration Survey (DMM).

Those who move voluntarily to better jobs make up less than half ( 45.7 percent) of the ten percent who say they move for employment reasons. A further 16.9 percent respond to largely involuntary factors such as being transferred, losing a job or retiring and a further fifth are classified by coders as 'other reasons'. What is rarely recognised however is that a substantial number of migrants cite employment reasons for moving within their local labour market, in order to be closer to their workplace (16.2 percent), in order to, in Zax's terminology, move along their housing price and wage function.

Table 7: Employment motivations for moving within and between local labour markets in New Zealand. Male and female $18<65$ years. (Column percentages in italics)

\begin{tabular}{lccr}
\hline $\begin{array}{l}\text { Employment reasons } \\
\text { for moving from origin }\end{array}$ & Intra-LMA & Inter-LMA & Total \\
\hline Take up new job promotion & 16.0 & 97.0 & 113.0 \\
& 9.3 & 30.0 & 22.7 \\
Look for job opportunities & 33.0 & 78.0 & 111.0 \\
Transfer & 19.1 & 23.9 & 22.2 \\
& 7.0 & 24.0 & 31.0 \\
Lost job & 4.0 & 7.4 & 6.2 \\
& 12.0 & 14.0 & 26.0 \\
Retired & 6.9 & 4.3 & 5.2 \\
& 18.0 & 13.0 & 31.0 \\
Closer to workplace & 10.4 & 4.0 & 6.2 \\
& 54.0 & 25.0 & 79.0 \\
Other reasons & 31.2 & 7.7 & 15.8 \\
& 33.0 & 75.0 & 108.0 \\
Total & 19.1 & 23.0 & 21.6 \\
\hline
\end{tabular}

Source: Statistics New Zealand, Dynamics of Motivation and Migration Survey (DMM). 
It is not merely the presence of employment reasons which separates intra from inter-LMA movers but the specific employment reason. Table 7 shows how the distribution over the different categories of employment reasons shifts according to whether the move takes place within or between local labour markets. Moving to be closer to the workplace is much more likely to be mentioned by those moving within the LMA; 31 percent compared to under 8 percent. Those moving for employment reasons within LMAs are also more likely to say they moved because they lost their job or retired.

The importance of Table 7 lies in the way it uncovers the range of reasons we call 'employment' but especially the way it highlights the much more limited number of moves designed to increase the financial returns to employment. Both take place within and between local labour markets. Over eighty percent of those moving to take up a new promotion change LMAs but almost a third of those searching for new work say that is why they changed their address within their LMA. Retirement and losing a job is also likely to precipitate more movement within LMAs.
Instructive though these results are they still omit one important dimension - distance of the move. LMAs vary in size and inter-LMA moves can range from very short to very long moves. It is important therefore that we complement our distinction between LMAs with distance if we are to better understand the adjustment process.

\section{Section 7. Distances moved}

We calculated migration distances within and between our local labour markets based on the centroid of the census area unit of origin and destination and then related these to the motivations given for moving from the origin. As expected, the average length of a move is always longer when moves take place between local labour markets, regardless of reason, as Figure 2 shows. Within LMAs the employment motivated moves are the longest as one may also have anticipated, but, contrary to much of the northern hemisphere literature, the longest moves between LMAs are actually those driven by social, educational, and environmental imperatives rather than employment.

\section{Figure 2: Distance moved (in natural logarithms) within and between local labour market areas (LMAs) by}

main reason for moving within New Zealand over the two year period 2005 and 2006

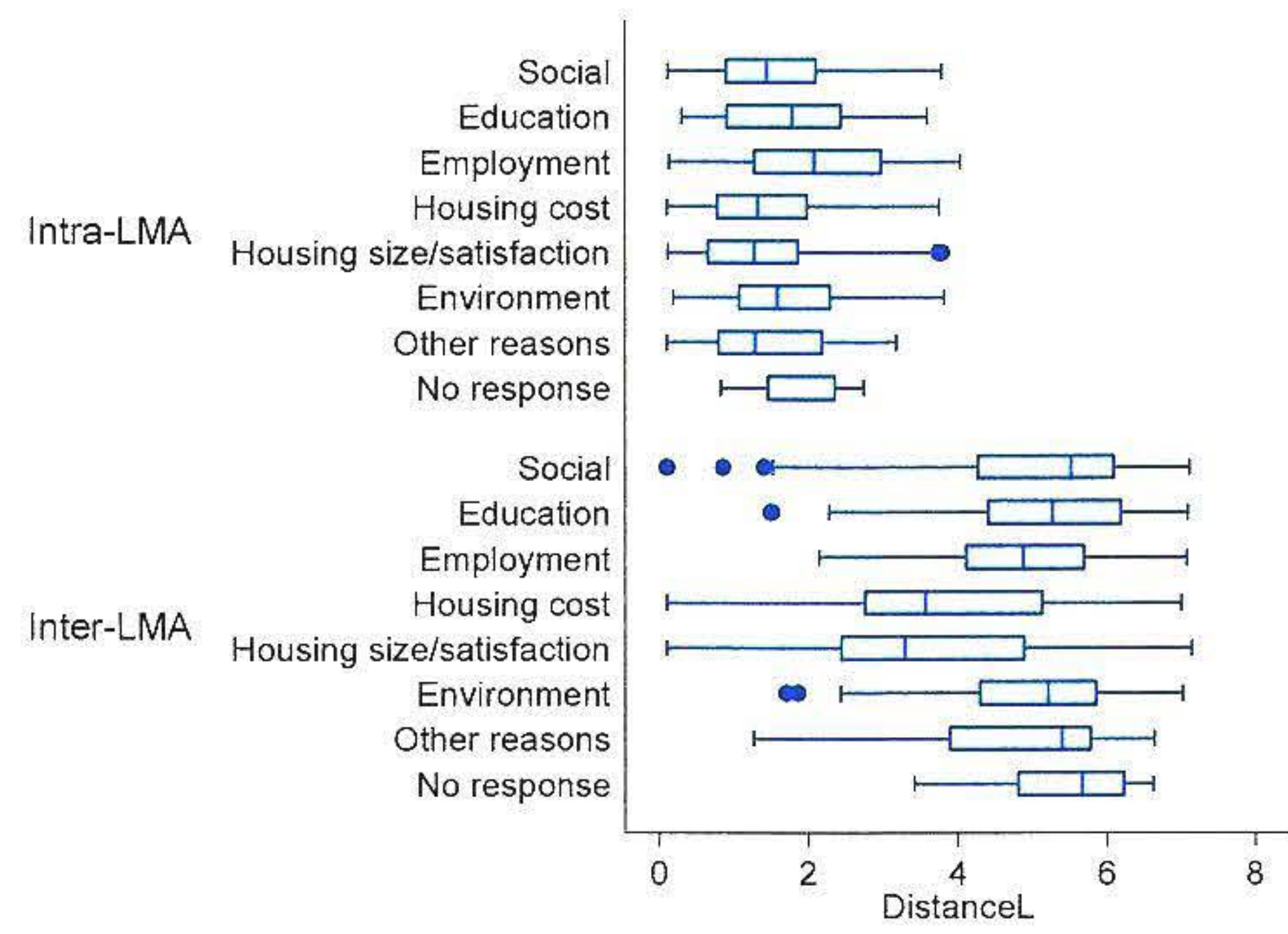

Source: Statistics New Zealand, Dynamics of Motivation and Migration Survey (DMM).

We delve a little deeper into this last result by asking how the characteristic of the move relates to the type of employment reason movers offer. Once again, the average length of move between LMAs for employment reasons always exceeds those that take place for similar reasons within LMAs, Figure 3. However the ordering by distance differs in the two cases. Those moving to new jobs and for promotion within LMAs undertake the longer moves on average whereas those moving between LMAs are more likely to have either lost their job, transferred or retired. In other words, it looks as though those involved in involuntary changes to employment are more likely to have to changed address over the longer distances. Those who lost their job move the shortest median distance within LMA but the longest between
LMAs. Those moving between LMAs are also shorter than other employment driven moves because LMA boundaries do not subsume all commuters between the $\mathrm{CBD}$ and outer suburbs and ex-urban areas lying within adjacent LMAs (also see Goodyear and Ralphs, 2009).

In summary, contrary to the UK and USA evidence, in the much smaller New Zealand case long distance moves are not disproportionately governed by employment considerations. And those employment motivated moves which do involve longer distances are driven less by those voluntary adjustments which are often assumed than by involuntary entry and exits from the market. What remains to be identified is who moves for employment reasons? 
Figure 2: Distance moved (in natural logarithms) within and between local labour market areas (LMAs) by employment reasons for moving from the origin within New Zealand over the two year period 2005 and 2006

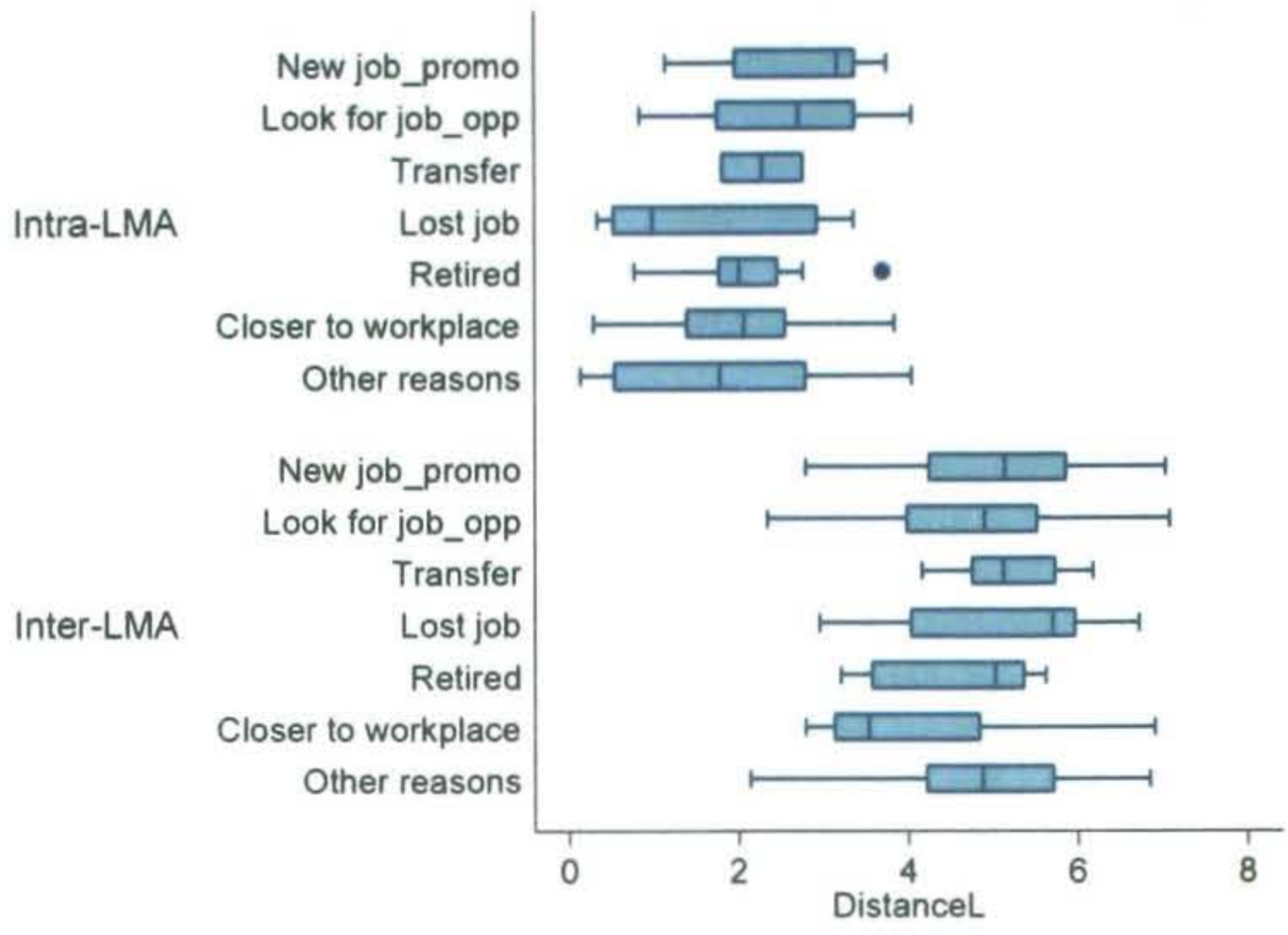

Source: Statistics New Zealand, Dynamics of Motivation and Migration Survey (DMM).

Table 8: The estimated probability of moving within New Zealand for employment reasons. Male and female $18<65$ years

Males

\begin{tabular}{lrrrrr}
\hline Variable & dy/dx & Std.Err. & $\mathrm{z}$ & $\mathrm{P}>|\mathrm{z}|$ & $\mathrm{Mean}$ \\
\hline Age 16-24 & 0.014 & 0.026 & 0.56 & 0.577 & 0.202 \\
Age 25-34 & 0.002 & 0.022 & 0.11 & 0.912 & 0.295 \\
Age 45-54 & 0.003 & 0.026 & 0.14 & 0.887 & 0.159 \\
Age 55-64 & 0.075 & 0.043 & 1.75 & 0.079 & 0.068 \\
Proportion with no qualifications & -0.012 & 0.018 & -0.66 & -0.511 & 1.298 \\
One or more qualifications since leaving school & 0.004 & 0.017 & 0.25 & 0.802 & 0.622 \\
Employed & -0.073 & 0.050 & -1.45 & 0.147 & 0.926 \\
Unemployed & 0.007 & 0.053 & 0.13 & 0.895 & 0.036 \\
Maori & -0.003 & 0.025 & -0.14 & 0.889 & 0.111 \\
Pacific Island Polynesian & -0.066 & 0.028 & -2.37 & 0.018 & 0.056 \\
Chinese & 0.023 & 0.050 & 0.46 & 0.648 & 0.034 \\
Indian & -0.077 & 0.029 & -2.59 & 0.009 & 0.048 \\
Born in New Zealand & 0.017 & 0.021 & 0.81 & 0.420 & 0.754 \\
\hline
\end{tabular}

Note: $\mathrm{N}=1744, \mathrm{LR}$ chi2 $(13)=21.42$, Prob $>\mathrm{CHI} 2=0.065$, pseudo $\mathrm{R} 2=0.015$

Females

\begin{tabular}{lrrrrr}
\hline Variable & $\mathrm{dy} / \mathrm{dx}$ & Std.Err. & $\mathrm{z}$ & $\mathrm{P}>|\mathrm{z}|$ & $\mathrm{Mean}$ \\
\hline Age 16-24 & 0.012 & 0.022 & 0.58 & 0.562 & 0.211 \\
Age 25-34 & -0.006 & 0.018 & -0.34 & 0.738 & -0.042 \\
Age 45-54 & 0.002 & 0.022 & 0.11 & 0.913 & 0.165 \\
Age 55-64 & 0.043 & 0.037 & 1.15 & 0.251 & 0.058 \\
Proportion with no qualifications & -0.002 & 0.017 & -0.15 & 0.879 & 1.262 \\
One or more qualifications since leaving school & 0.021 & 0.014 & 1.47 & 0.142 & 0.596 \\
Employed & -0.000 & 0.024 & -0.03 & 0.972 & 0.875 \\
Unemployed & 0.052 & 0.055 & 0.94 & 0.346 & 0.032 \\
Maori & -0.011 & 0.019 & -0.56 & 0.572 & 0.145 \\
Pacific Island Polynesian & -0.042 & 0.028 & -1.48 & 0.138 & -0.099 \\
Chinese & 0.017 & 0.047 & 0.37 & 0.714 & 0.025 \\
Indian & -0.025 & 0.037 & -0.69 & 0.492 & 0.027 \\
Born in New Zealand & -0.002 & 0.019 & -0.15 & 0.878 & 0.786 \\
\hline
\end{tabular}

Note: $\mathrm{N}=1862$, LR chi2 $(13)=9.23$, prob $>$ chi2 $=0.75$, pseudo $R 2=0.008$

Source: Statistics New Zealand, Dynamics of Motivation and Migration Survey (DMM). 


\section{Section 8. Who moves for employment reasons?}

In order to establish who moves for employment reasons we estimate the probability of citing employment reasons for moving $\mathrm{p}(\mathrm{e})$ as a function of the attributes of the mover for men and women separately. While the model has less discriminatory power when applied at this level, several relevant points do emerge from the post-estimated marginal effects reproduced in Table 8 and they are summarised in Figure 4. The results are similar when estimated for the combined effect of both intra and interLMA moves and just the combined is offered here.
The first point to note in Figure 4 is that the employed are conservative when it comes to moving. They are also no more likely to cite employment reasons for moving than those in the working age population who are outside the labour force. And older workers are the most conservative therefore it is surprising to find that both men and women in the older age have a higher propensity to cite employment reasons than the base 35-45 age group. The reason has to do with their greater propensity to reduce their commute within their LMA.

Figure 4: The estimated probability of citing employment reasons for moving by the attribute of movers.

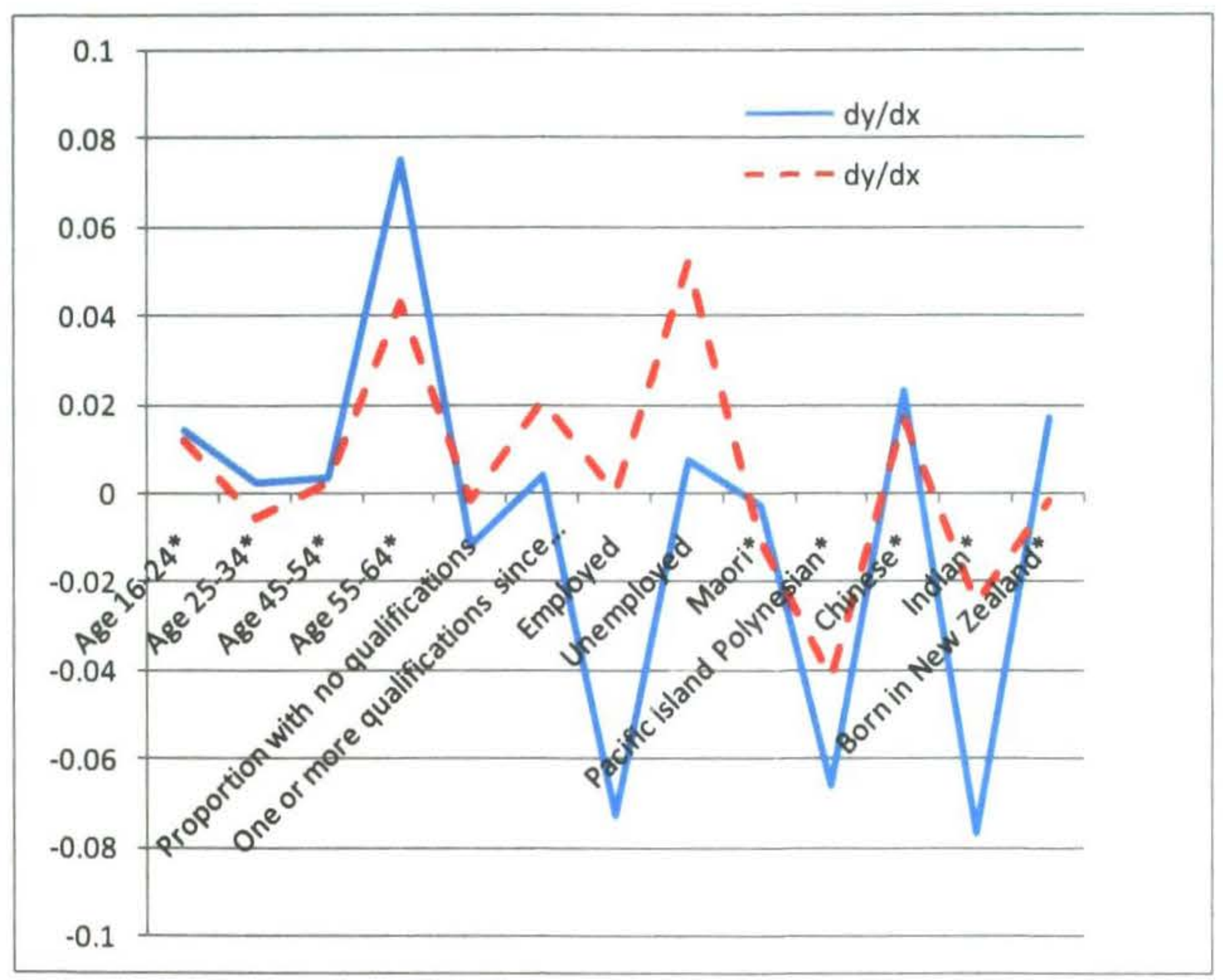

Source: Statistics New Zealand, Dynamics of Motivation and Migration Survey (DMM).

Employed men are considerably less likely to say they move for employment reasons and the unemployment differ little in this respect from those not in the labour force. Unemployed women however are noticeably more likely to say they moved for employment reasons which complements similar differences in the propensity of female unemployed to move (recall Table 2). Qualifications make little difference, but ethnicity does. Both Pacific Island Polynesian men and women are far less likely to give employment reasons for moving, a characteristic also shared by the smaller Indian population.

In summary, there is not a great deal of difference in the demographic and socio-economic characteristics of those movers who say they move primarily for employment reasons or for other reasons. With the exception of unemployed women and older age groups both of whom are more likely to cite employment as primary reasons for moving, few other attributes other than ethnicity separate employment motivated movers from non movers.

\section{Section 9. Conclusions}

We began this paper with the observation that although most models of population migration assume that members of the labour force migrate to enhance returns to their labour, major surveys suggest that only around 10 percent of all individuals who change residence say they are motivated primarily by employment reasons. We then asked how we could reconcile the apparent contradiction between the strong employment based assumptions of the neoclassical model of labour migration, the pattern of net flows that seem to support the model and the weak evidence on the relative importance of employment motivators from the major social surveys. 
That so few movers cite employment as their main reason for moving does not mean that employment is not important (cf Schachter, 2001), only that employment remains a necessary rather than a sufficient condition for moving. On-going employment is so important that most people get it out of the way as a given and focus their survey responses on the other more discretionary reasons for moving. "It is not very easy," as Gregg et al have pointed out, " to change location if there is no source of income" (Gregg et al., 2004), p. 394. Similarly, very few unemployed actually move without having secured alternative employment (Gordon, 1995).

Most see their move as a way of adjusting consumption or realigning social relationships rather than enhancing returns to employment and most moves are not associated with a gain in income. Most therefore view employment as an enabler of movement rather than as a primary reason for moving. Folded into this set may well be some for whom cognitive dissonance applies - those are less successful in securing the employment they want or expect at their destination and switch their reason from employment to consumption. We have no way of quantifying how common this rationalising behaviour might be.

While employment motivated moves are more likely to involve moves between LMAs, they are certainly not confined to such moves. And, far from being the primary reason for long distance moves, those employment based moves which are voluntary and driven by investment criteria are actually more localised. The more distant moves associated with employment reasons are most likely to be forced or involuntary moves. We also encountered employment reasons as a major driver of mobility within local labour market primarily in order to shorten the commute.

Labour migration may help equilibrate the national labour market in quantity terms by evening out unemployment differentials as predicted by the neoclassical model. There is a difference between this result, however and one which argues that moves between local labour markets are taken in order to improve returns to employment.

The difference between maintaining and improving returns to employment is an important distinction which is left uncovered simply by analysing the pattern of net migration flows. Only motivational questions or specific questions on returns before and after the move can actually uncover the relative importance of employment considerations in peoples decision to move (or stay).

Such conclusions are also supported by the nonmotivational evidence, the fact that after controlling for demographics neither labour force status nor occupation per se appear to either raise the probability of moving, or help us to discriminate between intra and inter labour market mobility. Where they are present, they have their strongest manifestations in the migration behaviour of women, not men. Women's internal migration is more sensitive to being employed (but not to being unemployed), to their higher education and being in the professions, results which are consistent with rising competition among educated women in the market place. But even among educated women, employment motivation per se still plays a relatively minor role as a motivator of both mobility and migration.

The contribution of our paper has been to place the role of employment in migration more firmly on an evidential footing. Far from being the major driver of either mobility or migration, it is the very necessity of work that is important. The need for a continuing income stream does two things: it makes people less inclined to move and, for those wishing to move as part of a life style or consumption based change, it constrains where they can move to. As a result net flows appear to support theories of migration change in which employment is argued to be the primary motivation. Only a small proportion of those migrating between LMAs report doing so in search of or to realise gains to employment. Our evidence suggests that it is consumption, associated life style, family and social reasons which are the prime drivers of movement both within and between LMAs. For most people employment is only important as an enabler of movement not as a primary reason for the move.

\section{Future research}

There are several directions we plan to take this work. There are advantages in paying more attention to the perceived returns to migration made for employment and non-employment reasons (as well as type of employment reason), both in terms of perceived changes in income and in satisfaction following the move. The later is currently being addressed by $\mathrm{PhD}$ student, Michael Sloan. This paper has paid no attention to the geography of movement other than addressing distance moved. However characteristics of origin and destination are likely to play a role in influencing who is motivated to move for employment reasons. We already know that the reasons given for leaving the place of origin differ from those for choosing the destination and that employment plays a stronger role in the latter.

\section{Acknowledgements}

Funding from the Royal Society of New Zealand through an International Science and Technology (ISAT) linkages has facilitated the above collaboration between Victoria University of Wellington, the University of California Los Angeles (UCLA) and Statistics New Zealand. The authors appreciate the funding provided by the School of Geography, Environment and Earth Sciences, Victoria University of Wellington to access the survey unit record files via the Statistics New Zealand Data Lab.

We wish to acknowledge the computing assistance offered by $\mathrm{PhD}$ student Michael Sloan and Jamie Newell's supply of the labour market area concordance file. The paper has been improved as a result of comments on an earlier draft by Jacques Poot, University of Waikato. 
1. The third possibility, which we plan to explore later in this project, is that any migrants driven by employment motivated 'heads of household' probably carry with them a number of tied movers - household members who would have been quite content to stay where they were if the decision were entirely theirs. To the extent that these tied movers do not share the same enthusiasm for moving to improve employment returns, they will return other motives.

2. For a useful discussion on the subtleties see Gregg, P., Machin, S. and Manning, A. 2004: Mobility and joblessness. In Card, D., Blundell, R. and Freeman, R., editors, Seeking a premier league economy: NBER, University of Chicago Press, 371-410., p 385.

3. The fact that investment decisions may compete with the consumption considerations may account for the wage premiums offered in locations which may be suboptimal in consumption terms, Glaeser, E.L. and Maré, D.C. 2001: Cities and skills. Journal of Labor Economics 19, 316-342., a result which recent work on the geography of happiness tends to support Morrison, P.S. 2010: Local expressions of subjective well-being: the New Zealand experience. Regional Studies (forthcoming).

4. Data collection for DMM was done by computer assisted interviewing (CAI). Data was collected partly by computer assisted personal interviewing (CAPI) by field staff for selected households (about 30 percent). The remaining households were surveyed by centralised computer assisted telephone interviewing (CATI).

5. The target population for the DMM survey is the usually resident, civilian population of New Zealand aged 15 years and over and living in occupied private dwellings. However, individuals of the household were ineligible for the personal DMM survey if the household was ineligible for HLFS. The HLFS weighted response rate for the March 2007 quarter was 88.7 percent, and the proportion of these individuals responding to DMM was 87.8 percent. Therefore the overall response rate for the DMM survey was $0.887 \mathrm{x}$ $0.878=0.779$. The non-response to DMM is partly due to the increased burden of it being a supplement and partly due to proxy responses not being accepted (even though they were accepted for HLFS). Information on sampling errors for each data cell in the cross tabulations SNZ provide to users (the downloadable tables) is available upon request.

6. In addition to the satisfaction rating given to employment opportunities by stayers, there are two additional questions asked in the DMM survey which could also throw additional light on the relationship between employment and mobility: the rating given by movers of employment opportunities compared with before the move (for those for whom the question is relevant) and how movers responded when asked whether their personal annual income increased, decreased or stayed the same after they moved, and in a separate question whether this increase or decrease was related to their move. These additional data will be incorporated later in the project.

7. In practice these authors do not actually model the reported reasons for moving. They focus instead on the reasons put forward for planning to move and they follow up movement behaviour that occurred over successive waves (rather as Kan did using the PSID, Kan, K. 1999: Expected and unexpected residential mobility. Journal of Urban Economics 45, 72-96., Boheim, R. and Taylor, M. 1999: Residential mobility, housing tenure and the labour market in Britain. Essex University ILER Working paper Essex: Institute for Social and Economic Research.. Hughes and McCormick report a similar result, finding that personal unemployment increases an individual's propensity to migrate even though increasing duration of unemployment hinders mobility Hughes, G. and McCormick, B. 1989: Does migration reduce differentials in regional unemployment rates? In van Dijk, J., Folmer. H., Herzog, H.W. and Schlottmann, A.M., editors, Migration and labour market adjustment, Dordrecht: Kluwer.

8. Note here that employment status of movers refers to their state immediately before the move, for stayers their employment status is measured at the beginning and end of the mobility window (20052006 ), or more strictly speaking two years prior to the interview (which spanned a period of several months). Documenting labour force status before the move is an important attribute of the DMM survey for as Masnick showed in 1968, there are real difficulties in inferring an unknown employment status prior to or at the time of the migration from data on employment status available at the end of the migration interval Masnick, G.S. 1968: Employment status and retrospective and prospective migration in the United States. Demography 5, 79-85.

9. There is a strong rationale for estimating models of mobility separately for men and women as outlined in Gardner, Pieere and Oswald Gardner, J., Pierre, G. and Oswald, A. 2001: Moving for job reasons. Working paper, Warwick: Department of Economics. who observe that when women are in relationships they are less mobile than men for their own job reasons but more mobile for their partner's job reasons. Although not addressing this exact same issue, on their website Statistics New Zealand do show that male and female 
partners from the DMM survey show a very similar distribution of reasons for moving. Whether this correspondence applies within individual households as opposed to over the population of movers as a whole has not been investigated.

10. Although tangential to the main story, the coefficients on the primary control variables reported in Table 2 are worth noting. The highly significant influence of age is consistent with the international evidence: the probability of moving within the two year period falling monotonically with early ten year age groups. Males between 15 and 25 show a 14 percent greater likelihood than the base of $35<45$ year olds. Those $55<65$ are 19 percent less likely to have moved. The result is similar for women although there is a higher probability of moving by younger females and a relatively lower probability among older women. Simply obtaining a school qualification makes no identifiable difference to the likelihood of moving for either men or women but post-school qualifications are influential, raising the chances of moving within the two year period by 5.5 and 3.9 percent respectively. The influence of ethnicity is always quite country specific and in this New Zealand case primary interest centres on Maori. In the case of men, Maori show little real difference to the primarily European base. Neither do the Chinese and it is only Indian men ( 3.3 percent of the population) in this instance who show a statistically significant tendency to move more often than European ( 7.6 percent). There is some evidence that mobility rates may be relatively lower for Pacific Island men. Among women Maori women show a greater likelihood of moving, a result which stands in contrast to the other non-European women, most notably Pacific Island women, who show a lower probability of moving. Finally, being born in New Zealand apparently has a stabilising effect, reducing the probability of moving by both men and women by over five percent. This is consistent with recent evidence on higher migration rates of immigrants, Stillman, S. and Mare, D.C. 2007: The impact of immigration on the geographic mobility of New Zealanders. Motu Working Paper 07-05, Wellington Motu Economic and Public Policy Research

11. Gordon draws on the UK Labour Force survey in order to explore the type of moves people make Gordon, I. 1995: Migration in a segmented labour market. Transactions of the Institute of British Geographers 20, 139-155. He concludes that those moving for employment reasons often do so with internal market of the same firm and line up positions well before they move. These sponsored moves stand in contrast to the text book speculative moves and Gordon seeks to explain the differences in attributes of those undergoing the two types of employment driven migration.
12. In a recent extension of this early literature McKinnish draws on the Public Use Microdata sample from the 2000 US decennial census to demonstrate that contemporary mobility rates (between metropolitan areas) rise with the level of education (for males) and that migration rates rise with the average wage. McKinnish's Table 1 page 833 for non-Hispanic, white, native born married couples both partners aged 25-55 reporting occupation for last job worked in last five years (excluded if one or both partners not employed in last five years).

13. For a discussion of coder bias in such classifications see Niedomysl, T. and Malmberg, B. 2009: Do open-ended survey questions on migration motives create coder variability problems? Population, Space and Place 15, 79-87. No such analysis has been undertaken on the DMM survey but the Swedish case does not suggest any systematic bias.

14. The original category of 'economic' was changed to its more specific label, housing cost, and a more specific 'housing size/satisfaction' category was created. These changes render our results slightly different from those reported on the Statistics New Zealand website for the DMM survey: see http://www.stats.govt.nz/reports/people/surveydynamics-motivations-migration-in-nz-additionaltables.aspx

15. There is therefore scope in future stages of this research to see the extent to which employment reasons are ventured as secondary or tertiary reasons.

16. The DMM survey also asks those who did not move why they stayed and although we do not cover these results in this paper it is worth noting that employment considerations are typically more important in accounting for why people stay than why they move, about 14 percent vs 11 percent as reported in the tables released on the web by Statistics New Zealand. Questions on why people skay in their residence and do not move are rarely asked in the overseas social surveys cited above and appear less often in the literature, although see Hanson, S. 2005: Perspectives on the geographic stability and mobility of people in cities. Proceedings of the National Academy of Sciencs of the United States of America (spatial demography special feature) 102, 15301-15306.

\section{References}

Blackburn, M.L. (2006). The impact of internal migration on married couple's earnings in Britain, with a comparison to the United States. ISER Working Paper Colchester: University of Essex. 
Blanchflower, D.G. (1996). Youth labour markets in twenty three countries. A comparison using micro data. In Stern, D., editor, School to work policies and practices in thirteen countries, Cresskill: Hampton Press.

Boheim, R. and Taylor, M. (1999). Residential mobility, housing tenure and the labour market in Britain. Essex University ILER Working paper Essex: Institute for Social and Economic Research.

Boheim, R. and Taylor, M. (2000). Residential mobility, housing tenure and the labour market in Britain. Essex University ILER Working paper Essex: Institute for Social and Economic Research.

Boheim, R. and Taylor, M. (2007). From the dark end of the street to the bright side of the road? The wage returns to migration in Britain. Labour Economics 14, 99-117.

Borjas, G., Bronars, S.G. and Trejo, S.J. (1992). Selfselection and internal migration in the United States. Journal of Urban Economics 32, 159-185.

Chen, Y. and Rosenthal, S.S. (2008). Local amenities and life-cycle migration: Do people move for jobs or fun? Journal of Urban Economics 64, 519-537.

Clark, W.A.V. and Huang, Y. (2004) Linking migration and mobility: individual and contextual effects in British Housing Markets. Regional Studies 38, 617-628.

Clark, W.A.V. and Withers, S.D. (2007) Family migration and mobility sequences in the United States: spatial mobility in the context of the life course. Demographic Research (Max Planck Institute for Demographic Research) 17, Number 20, 591-622.

DaVanzo, J. and Morrison, P. (1981). Return and other sequences of migration in the United States. Demography 18, 85-102.

Fotheringham, A.S., Champion, T., Wymer, C. and Coombes, M. (2000). Measuring de'stination attractivity: a migration example. International Journal of Population Geography 6, 391-421.

Gardner, J., Pierre, G. and Oswald, A. (2001). Moving for job reasons. Working paper, Warwick: Department of Economics.

Glaeser, E.L. and Maré, D.C. (2001). Cities and skills. Journal of Labor Economics 19, 316-342.

Goodyear, R. and Ralphs, M. (2009). Commuting patterns in New Zealand: 1996-2006. Wellington Statistics New Zealand.

Gordon, I. (1995). Migration in a segmented labour market. Transactions of the Institute of British Geographers 20, 139-155.
Gregg, P., Machin, S. and Manning, A. (2004). Mobility and joblessness. In Card, D., Blundell, R. and Freeman, R., editors, Seeking a premier league economy: NBER, University of Chicago Press, 371-410.

Grigg, D.B. (1977). E.G. Ravenstein and the 'laws of migration'. Journal of Historical Geography 3, 4154.

Hanson, S. (2005). Perspectives on the geographic stability and mobility of people in cities. Proceedings of the National Academy of Sciencs of the United States of America (spatial demography special feature) 102, 15301-15306.

Harris, J.R. and Todaro, M.D. (1970). Migration, unemployment and development: A two sector analysis. American Economic Review 60, 126-142.

Herzog, H.W., Schlottman, A.M. and Boehm, T.P. (1993). Migration as spatial job-search; a survey of empirical findings. Regional Studies 27, $327-$ 340 .

Hughes, G. and McCormick, B. (1989). Does migration reduce differentials in regional unemployment rates? In van Dijk, J., Folmer, H., Herzog, H.W. and Schlottmann, A.M., editors, Migration and labour market adjustment, Dordrecht: Kluwer.

Kan, K. (1999) Expected and unexpected residential mobility. Journal of Urban Economics 45, 72-96.

Khwaja, Y. (2002). 'Should I stay or should I go? Migration under uncertainty: the real options approach' Economics and Finance Discussion Pupers 02-10, London: Economics and Finance Section, School of Social Sciences, Brunel University

Lansing, J.B. and Mueller, E. (1967). The geographic mobility of labour Ann Arbor, Michigan: Survey Research Centre, University of Michigan.

Lee, E.S. (1966). A theory of migration. Demography 3. 47-57.

Maré, D. and Timmins, J. (2004). Internal migration and regional labour markets in New Zealand. Wellington Motu Economic and Public Policy Research.

Masnick, G.S. (1968). Employment status and retrospective and prospective migration in the United States. Demography 5, 79-85.

McCormick, B. (1997). Regional unemployment and labour mobility in the UK. European Economic Review 41, 581-589.

Morrison, P.S. (2005). Unemployment and urban labour markets. Urban Studies 42, 2261-2288. 
Morrison, P.S. (2010). Local expressions of subjective well-being: the New Zealand experience. Regional Studies (forthcoming).

Niedomysl, T. and Malmberg, B. (2009). Do openended survey questions on migration motives create coder variability problems? Population, Space and Place 15, 79-87.

Nissen, K. and Didham, R. (2008) Moving to New Zealand: reasons and patterns of settlement: some results from the Survey of Dynamics and Motivations for Migration in New Zealand. Wellington Population Statistics Unit, Statistics New Zealand.

Papps, K.L. and Newell, J.O. (2002). Identifying functional labour market areas in New Zealand: a reconnaissance study using travel-to-work data. Bonn: Institute for Study of Labour.

Ritchey, P.N. (1976). Explanations of migration. Anmual Review of Sociology 2, 363-404.

Rosen, S. (1986). The theory of equalizing differences. In Ashenfelter, O. and Card, D., editors, The Handbook of Labor Economics: Elsevier Publishers, 641-692.

Saben, S. (1964). Geographic mobility and employment status, March 1962-March 1963. Monthly Labour Review 87, 873-881.

Schachter, J. (2001). Why people move: exploring the March 2000 current population survey. Current Population Reports: US Census Bureau.

Shields, G. and Shields, M. (1989). The emergence of migration theory and a suggested new direction. Journal of Economic Surveys 3, 277-304.

Simmons, J.W. (1968). Changing residence in the city: a review of intra-urban mobility. Geographical Review 58, 622-651.

Sjaastad, L.A. (1962). The costs and returns of human migration. Journal of Political Economy 70, 8093.

Stillman, S. and Mare, D.C. (2007). The impact of immigration on the geographic mobility of New Zealanders. Motu Working Paper 07-05,
Wellington Motu Economic and Public Policy Research.

Topel, R.H. and Ward, M.P. (1992). Job mobility and the careers of young men. Quarterly Journal of Economics 107, 439-480.

Zax, J.S. (1991). The substitution between moves and quits. The economic Journal 101, 1510-1521.

Zax, J.S. (1993). When is a move a migration? Regional Science and Urban Economics 24.

Zodgekar, A. and Seetharam, K.S. (1972). Interdivisional migration differentials by education for groups of selected SMSA's, United States, 1960. Demography 9, 683-699.

\section{Author}

Philip S. Morrison

School of Geography

Environment and Earth Sciences

Victoria University of Wellington

P.O. Box 600

Wellington

Philip.Morrison@vuw.ac.nz

William A.V. Clark

Department of Geography

1255 Bunche Hall

UCLA

Los Angeles

California 90095.

wClark@geog.ucla.edu

Kirsten Nissen

Statistics New Zealand

Statistics House

The Boulevard

Harbour Quays

PO Box 2922

Wellington 6140

Kirsten.Nissen@stats.govt.nz

Robert Didham

Statistics New Zealand

Statistics House

The Boulevard

Harbour Quays

PO Box 2922

Wellington 6140

Robert.Didham@stats.govt.nz 